11 Vaughan NJA, Oakley NW. Treatment of diabetes in pregnancy. Clin Obstet Gynecol 1986;13:291-306.

12 Hagay ZJ, Reece EA. Diabetes mellitus in pregnancy. In: Reece EA Hobbins JC, Mahoney MJ, Petrie RH, eds. Medicine of the fetus and mother. Philadelphia: Lippincott, 1992.

13 Weiss PAM, Hofmann H. Intensified conventional insulin therapy for the pregnant diabetic patient. Obstet Gynecol 1984;64:629-37.

14 The Diabetes Control and Complications Trial Research Group. Pregnancy outcomes in the diabetes control and complications trial. Am J Obstet Gynecol 1996;174:1343-53.

15 Hare JW, White P. Gestational diabetes and the White classification Diabetes Care 1980;3:394.

16 Brenner WE, Edelman DA, Hendricks CH. A standard of fetal growth for the United States of America. Am J Obstet Gynecol 1976;126:555-64

17 Pedersen J. The pregnant diabetic and her newborn. Baltimore, MD: Williams and Wilkins, 1967.

18 Mountain KR. The infant of the diabetic mother. Baillière's Clin Obstet Gynecol 1991;5:413-42.

19 Spellcy WN, Miller S, Winegar A, Peterson PQ. Macrosomia-maternal characteristics and infant complications. Obstet Gynecol 1985;66:158-61.

20 Jarrett RJ. Reflection on gestational diabetes mellitus. Lancet 1981;2:1220-1.
21 Green JR, Schumacher LB, Pawson IG, Partridge JC, Krechmenr N. Influence of maternal body habitus and glucose tolerance on birthweight Obstet Gynecol 1991;78:235-40.

22 Leonardi MR, Bottoms SF. Increased incidence of large for gestational age infants not attributable to gestational diabetes. Am J Obstet Gynecol 1996;174:393.

23 Martin AO, Simpson JL, Ober C, Frenkel N. Frequency of diabetes mellitus in mothers of probands with gestational diabetes: possible maternal influence on the predisposition to gestational diabetes. Am J Obstet Gymecol 1985; 151:471-5.

24 Pettitt DJ, Aleck KA, Baird HR, Carraher MJ, Bennett PH, Knowler WC. Congenital susceptibility to NIDDM. Role of intrauterine environment. Diabetes 1988:37:622-8.

25 Dörner J, Steindel E, Tholke H, Sehliak V. Evidence for decreasing prevalence of diabetes mellitus in childhood apparently produced by prevention of hyperinsulinism in the foetus and newborn. Exp Clin Endocrino $1984 ; 84: 134-42$

26 Dunbar JM, Madden PM, Gleeson DT, Fiad TM, McKenna TJ. Premixed insulin preparations in pen syringes maintain glycemic control and are preferred by patients. Diabetes Care 1994;17:874-8.

(Accepted 16 August 1999)

\title{
Vertical transmission rates for HIV in the British Isles: estimates based on surveillance data
}

\author{
Trinh Duong, A E Ades, Diana M Gibb, Pat A Tookey, Janet Masters
}

\begin{abstract}
Objective To estimate and interpret time trends in vertical transmission rates for HIV using data from national obstetric and paediatric surveillance registers. Design Prospective study of HIV infected women reported through obstetric surveillance. HIV infection status of the child and onset of AIDS were reported through paediatric surveillance. Rates of vertical transmission and progression to AIDS rate were estimated by methods that take account of incomplete follow up of children with indeterminate infection status and delay in AIDS reporting.

Setting British Isles.

Subjects Pregnant women infected with HIV whose infection was diagnosed before delivery, and their babies.
\end{abstract}

Main outcome measures Mother to child transmission of infection and progression to AIDS in children.

Results By January 1999, 800 children born to diagnosed HIV infected women who had not breast fed had been reported. Vertical transmission rates rose to $19.6 \%(95 \%$ confidence interval $8.0 \%$ to $32.5 \%)$ in 1993 before falling to $2.2 \%(0 \%$ to $7.8 \%)$ in 1998. Between 1995 and 1998 use of antiretroviral treatment increased significantly each year, reaching $97 \%$ of live births in 1998 . The rate of elective caesarean section remained constant, at around 40\%, up to 1997 but increased to $62 \%$ in 1998 . Caesarean section and antiretroviral treatment together were estimated to reduce risk of transmission from $31.6 \%$ ( $13.6 \%$ to $52.2 \%)$ to $4.2 \%$ ( $0.8 \%$ to $8.5 \%)$. The proportion of infected children developing AIDS in the first 6 months fell from $17.7 \%$ (6.8\% to 30.8\%) before 1994 to $7.2 \%$ ( $0 \%$ to $15.7 \%$ ) after, coinciding with increased use of prophylaxis against Pneumocystis carinii pneumonia.

Conclusions In the British Isles both HIV related morbidity and vertical transmission are being reduced through increased use of interventions.

\section{Introduction}

Randomised controlled trials have established that zidovudine can significantly reduce the risk of vertical transmission of HIV. ${ }^{1}$ The protective effect of elective caesarean section has been confirmed by a recent meta-analysis of cohort studies ${ }^{2}$ and a randomised controlled trial. ${ }^{3}$ The combined effect of these interventions is reported to reduce transmission to $2 \%$ or less in some cohort studies. ${ }^{24}$

However, the general population of infected women may differ from those recruited into trials or cohort studies in terms of adherence to antiretroviral treatment, previous exposure to antiretroviral treatment, and uptake of elective caesarean section. It is therefore essential to monitor uptake of interventions and vertical transmission rates in the wider population. Here we present estimates of HIV vertical transmission rates in the British Isles. ${ }^{5}$

\section{Methods}

\section{Population studied}

Since 1989 pregnant women in the British Isles known to be infected with HIV have been notified to the Royal College of Obstetricians and Gynaecologists. Obstetricians are asked to report on outcome of pregnancy and, since 1995, on mode of delivery and uptake of antiretroviral treatment. After initial notification of children born to infected mothers to the British paediatric surveillance unit, paediatricians are asked for diagnostic and clinical data. Subsequently, children of indeterminate infection status are followed until infection status is known. ${ }^{5}$ All reporting is voluntary and confidential. This analysis is confined to prospectively ascertained children whose mothers' HIV infection was reported to have been diagnosed before delivery.

\section{Statistical methods}

Statistical methods to avoid biased estimation of vertical transmission rates due to incomplete follow up of
Editorial by Nicoll

Department of Epidemiology and Public Health, Institute of Child Health, London WC1N 1EH

Trinh Duong statistician A E Ades reader

Pat A Tookey senior research fellow Janet Masters research assistant

Clinical Trials Unit, Medical Research Council, Mortimer Market Centre,

London

WC1E 6AU

Diana M Gibb senior lecturer in epidemiology

Correspondence to: A E Ades a.ades@ich. ucl.ac.uk

BMJ 1999;319:1227-9

website extra

A longer version of this paper is available on the BMJ's website

www.bmj.com 
indeterminates ${ }^{6}$ were adapted and extended. These involve estimating the probability of infection for each indeterminate child based on when they were last known to be seropositive and the fact that they have not yet been reported to have AIDS. The method takes account of AIDS incubation time, delay in AIDS reporting, and time to antibody loss in uninfected children. It was assumed that progression to AIDS in the first six months would have been reduced since 1994 because prophylaxis against Pneumocystis carinii pneumonia became routine at that time following UK and US guidelines. ${ }^{7-8}$

The estimation-maximisation algorithm was used to estimate yearly vertical transmission rates since 1984, and the effect of mode of delivery and antiretroviral treatment during 1995 to 1998. Confidence intervals were estimated by bootstrap sampling from the data $(\mathrm{n}=999) .{ }^{9}$ Assumptions on date when $P$ carinii prophylaxis became routine and on distribution of delay in AIDS reporting were subjected to sensitivity analysis.

Table 1 Infection status of infants born to diagnosed, HIV infected women between 1984 and 1998 who were not reported to have been breast fed, and vertical transmission rates estimated with estimation-maximisation algorithm

\begin{tabular}{lccccc}
$\begin{array}{l}\text { Year of } \\
\text { birth }\end{array}$ & $\begin{array}{c}\text { Total live } \\
\text { births }\end{array}$ & Negative & $\begin{array}{c}\text { Positive } \\
\text { (AIDS) }\end{array}$ & Indeterminate & $\begin{array}{c}\text { Estimated vertical } \\
\text { transmission rate } \\
\text { (95\% CI) }\end{array}$ \\
\hline 1984 & 3 & 1 & $1(0)$ & 1 & \\
\hline 1985 & 17 & 10 & $3(2)$ & 4 & $9.6^{*}(2.1$ to 18.7$)$ \\
\hline 1986 & 36 & 31 & $1(0)$ & 4 & $5.7(0$ to 14.2$)$ \\
\hline 1987 & 38 & 30 & $2(2)$ & 6 & $16.5(5.5$ to 29.7$)$ \\
\hline 1988 & 38 & 29 & $6(4)$ & 3 & $8.0(0$ to 17.6$)$ \\
\hline 1989 & 41 & 32 & $3(1)$ & 6 & $16.6(5.4$ to 29.3$)$ \\
\hline 1990 & 41 & 27 & $6(4)$ & 8 & $10.6(0$ to 18.1$)$ \\
\hline 1991 & 53 & 36 & $4(2)$ & 13 & $19.6(8.0$ to 19.8$)$ \\
\hline 1992 & 55 & 38 & $5(1)$ & 12 & $19.3(9.7$ to 30.5$)$ \\
\hline 1993 & 52 & 28 & $8(2)$ & 16 & $18.9(8.4$ to 30.8$)$ \\
\hline 1994 & 69 & 38 & $10(1)$ & 21 & $14.1(6.4$ to 22.5$)$ \\
\hline 1995 & 61 & 36 & $9(1)$ & 16 & $6.8(1.6$ to 14.7$)$ \\
\hline 1996 & 91 & 58 & $10(3)$ & 23 & $2.2(0$ to 7.8$)$ \\
\hline 1997 & 85 & 52 & $4(0)$ & 29 & $12.1(9.7$ to 14.7$)$ \\
\hline 1998 & 120 & 42 & $1(0)$ & 77 &
\end{tabular}

*1984-6 estimate pooled, due to small numbers.

Table 2 Trends in mode of delivery and use of antiretroviral treatment 1995-8

\begin{tabular}{|c|c|c|c|c|}
\hline $\begin{array}{l}\text { Year of } \\
\text { birth }\end{array}$ & $\begin{array}{l}\%(\mathrm{No}) \text { of } \\
\text { elective } \\
\text { caesarean } \\
\text { sections }\end{array}$ & $\begin{array}{c}\%\left(\mathrm{~N}_{0}\right) \text { receiving } \\
\text { antiretroviral drugs }\end{array}$ & $\begin{array}{c}\% \text { (No) receiving >1 } \\
\text { antiretroviral drug }\end{array}$ & $\begin{array}{l}\% \text { (No) receiving all } \\
3 \text { components of } \\
\text { treatment }^{*}\end{array}$ \\
\hline 1995 & $42(24 / 58)$ & $66(40 / 61)$ & $0(0 / 39)$ & $54(15 / 28)$ \\
\hline 1996 & $38(32 / 85)$ & $77(66 / 86)$ & $3(1 / 36)$ & $85(50 / 59)$ \\
\hline 1997 & $42(35 / 84)$ & $84(70 / 83)$ & $26(18 / 70)$ & $86(54 / 63)$ \\
\hline 1998 & $62(74 / 119)$ & $97(115 / 119)$ & $57(66 / 116)$ & $89(93 / 104)$ \\
\hline
\end{tabular}

*Antenatal, during labour, and post partum to baby.

Table 3 Effects of elective caesarean section and antiretroviral treatment on vertical transmission rates of HIV, 1995-8 from logistic regression

\begin{tabular}{lccc} 
& $\begin{array}{c}\text { Vaginal/emergency } \\
\text { caesarean section }\end{array}$ & $\begin{array}{c}\text { Elective caesarean } \\
\text { section }\end{array}$ & $\begin{array}{c}\text { Adjusted odds ratio } \\
\text { (95\% Cl) }\end{array}$ \\
\hline No antiretroviral treatment & $31.6(13.6$ to 52.2$)$ & $15.3(3.4$ to 32.7$)$ & 1 \\
\hline Antiretroviral treatment & $10.1(4.6$ to 16.4$)$ & $4.2(0.8$ to 8.5$)$ & $0.24(0.08 \text { to } 0.76)^{\star}$ \\
\hline Adjusted odds ratio $(95 \% \mathrm{Cl})$ & 1 & $0.39(0.08$ to 1.04$) \dagger$ & \\
\hline${ }^{*} \chi^{2}{ }_{1}=6.9, P=0.009$. & & \\
$t \chi^{2}{ }_{1}=3.3, P=0.07$.
\end{tabular}

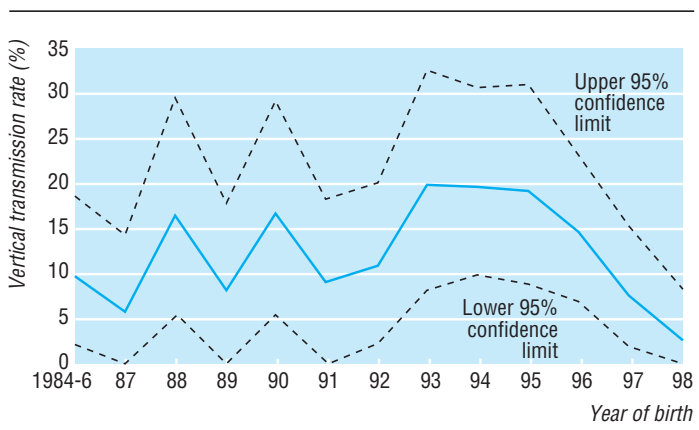

Year on year estimates of vertical transmission rates and $95 \%$ confidence intervals for HIV among children born to mothers known to be infected with HIV and who did not breast feed

\section{Results}

By the end of January 1999, a total of 800 prospectively ascertained non-breast fed children born to HIV infected women between 1984 and 1998 had been reported (table 1 ).

The overall estimation-maximisation algorithm estimate for vertical transmission, which removes the bias caused by indeterminate children, is $12.1 \%(9.7 \%$ to $14.7 \%)$. The transmission rate rose to $19.6 \%(8.0 \%$ to $32.5 \%)$ in 1993 and from 1995 decreased steeply to $2.2 \%(0 \%$ to $7.8 \%)$ in 1998 (figure). The decline in transmission rate from 1995 onwards was significant (odds ratio of 0.51 a year; $95 \%$ confidence interval 0.27 to $0.77, \chi_{2}^{2}=8.8, \mathrm{P}=0.003$ ).

Infected children progressed to AIDS within the first 6 months of life at an estimated baseline rate of $17.7 \%(6.8 \%$ to $30.8 \%)$ before 1994 and $7.2 \%(0 \%$ to 15.7\%) from 1994 onwards. The difference did not reach significance $\left(\chi^{2}=2.51, \mathrm{P}=0.11\right)$. After 6 months of age, an estimated $5.0 \%$ (2.4\% to $8.5 \%)$ of children who had not yet developed AIDS would do so each year.

Uptake of antiretroviral treatment increased significantly between 1995 and 1998, as did the proportion taking more than one antiretroviral drug (table 2). The proportion of mother-baby pairs receiving all three components of treatment ${ }^{1}$ (antenatal, during delivery, and post partum to the baby) also increased significantly.

Table 3 shows that the risk of HIV transmission was significantly lower in infants with exposure to antiretroviral treatment than in those without. The effect of caesarean section was not significant after antiretroviral treatment was adjusted for. The baseline transmission rate among infants delivered vaginally or by emergency caesarean section in the absence of antiretroviral treatment was estimated to be $31.6 \%$. Elective caesarean section or antiretroviral treatment alone reduced the transmission rate to $15.3 \%$ and $10.1 \%$, respectively, and when combined reduced transmission to $4.2 \%$.

\section{Discussion}

HIV vertical transmission rates rose gradually from 1984 to 1994 and then fell rapidly between 1995 and 1998. The earlier rise could be accounted for by changes in the epidemiology of HIV in infected women. $^{5}$ 
Key messages

- Reliable estimates of HIV vertical transmission rates can be derived from surveillance data

- Infected pregnant women are increasingly taking up elective caesarean section and antiretroviral treatment to reduce the risk of transmitting HIV to their babies

- Vertical transmission rates have fallen greatly over the past four years and progression to AIDS among infected children may also have slowed

- These benefits can occur only if infected women are diagnosed before or during pregnancy

In the four years ending 1998, during which uptake of elective caesarean section and antiretroviral treatment was increasing, the estimated vertical transmission rate fell steeply to $2.2 \%(0 \%$ to $7.8 \%)$ in 1998. This is comparable with a $2.0 \%$ estimate based on a meta-analysis, ${ }^{2}$ and $0.8 \%(1 / 133)$ in the French cohort ${ }^{4}$ among women taking antiretroviral treatment (mainly zidovudine only) and having an elective caesarean section. These findings are consistent with previously published data. ${ }^{10}$

Progression to AIDS (70\% of which was $P$ carinii pneumonia) within the first 6 months of life was reduced by nearly $60 \%$ in infants born after the beginning of 1994 compared with those born before. The effect was not significant, but a similar reduction of $66 \%$ in AIDS in infancy since 1993 was recently reported in the United States. ${ }^{11}$ This change is likely to be due to prophylactic co-trimoxazole given to most children born to infected women from 6 weeks of age. $^{78}$

Prospective cohort studies tend to be set in specialist centres, whereas randomised trials may use exclusion criteria. National surveillance data have the advantage of being population based but are more likely to suffer from missing data and less frequent follow up. However, as long as bias caused by children of indeterminate status is removed, surveillance data should accurately reflect vertical transmission rates in clinical practice. Trials may, in any case, become increasingly difficult to carry out. Antiretroviral treatment is becoming increasingly diverse, more women will have received antiretroviral treatment before pregnancy, and the transmission rates now being reported are very low. ${ }^{12-15}$ If the possibility of teratogenic effects becomes a major concern, ${ }^{16}$ compliance with treatment regimens may fluctuate. Surveillance data may eventually become the most reliable way to monitor uptake of interventions and HIV vertical transmission rates.

We thank obstetric and paediatric respondents to the surveillance schemes of the Royal College of Obstetricians and Gynaecologists and the British paediatric surveillance unit of the Royal College of Paediatrics and Child Health, as well as colleagues at the Communicable Disease Surveillance Centre, Colindale, and the Scottish Centre for Infection Environment and Health, Glasgow. We also thank David Dunn for help in developing the statistical methods.

Contributors: TD elaborated the statistical methods, programmed them, carried out the analyses, and drafted the methods and results section. AEA obtained funding for the surveillance (with Professor C S Peckham), conceptualised the analysis, and supported TD. TD and AEA are the guarantors. Introduction and discussion sections were drafted by DMG. PAT and JM assembled the surveillance data and assisted in its interpretation. All authors commented on all drafts of the paper.

Funding: TD, PAT, and JM were supported by grants from AVERT (Aids Education and Research Trust) and the Department of Health.

Competing interests: None declared.

1 Connor EM, Sperling RS, Gelber R, Kiselev P, Scott G, O'Sullivan MJ, et al. Reduction of maternal-infant transmission of human immunodeficiency virus type 1 with zidovudine treatment. Pediatric AIDS Clinical Trials Group Protocol 076 Study Group. N Engl J Med 1994;331:1173-80.

2 International Perinatal HIV Group. Mode of delivery and the risk of vertical transmission of human immunodeficiency virus type 1 . A meta-analysis of fifteen prospective cohort studies. $N$ Engl J Med 1999;340:977-87.

3 European Mode of Delivery Collaboration. Elective caesarean-section versus vaginal delivery in prevention of vertical HIV-1 transmission: a randomised clinical trial. Lancet 1999;353:1035-9.

4 Mandelbrot L, Le Chenadec J, Berrebi A, Bongain A, Benifla JL, Delfraissy JF, et al. Perinatal HIV-1 transmission. Interaction between zidovudine prophylaxis and mode of delivery in the French perinatal cohort. JAMA 1998;280:55-60.

5 Nicoll A, McGarrigle C, Brady T, Ades AE, Tookey PA, Duong T, et al. Epidemiology and detection of HIV-1 among pregnant women in the United Kingdom: results from national surveillance 1988-1996. BMJ 1998;316:253-8

6 Dunn DT, Ades AE. Estimating the HIV vertical transmission rate and the pediatric AIDS incubation period from prospective data. J Am Stat Assoc 1997;91:935-43.

7 Gibb DM, Walters S. Guidelines for management of children with HIV infection. Horsham: AVERT, 1993:1-29

8 US Public Health Service recommendations for human immunodeficiency virus counselling and voluntary testing for pregnant women. MMWR 1995:44:1-14.

9 Efron B, Tibshirani J. Bootstrap measures for standard errors, confidence intervals, and other measures of statistical accuracy. Stat Sci 1986;1:54-77.

10 Kind C, Rudin C, Siegrist CA, Wyler CA, Biedermann K, Lauper U, et al Prevention of vertical HIV transmission: additive protective effect of elective cesarean section and zidovudine prophylaxis. Swiss Neonatal HIV Study Group. AIDS 1998;12:205-10.

11 Lindegren ML, Byers B, Roger M, Wortley P, Fleming P. On the verge of elimination of perinatally acquired HIV/AIDS? Updated trends in the United States. 6th conference on retroviruses and opportunistic infections Chicago 1999; Abstract 228.

12 Fiscus S, Adimora AA, Schoenbach VJ, Wilfert C, Johnson VA. Can zidovudine monotherapy continue to reduce perinatal HIV transmission? The North Carolina experience 1993-1997. XII World AIDS Conference Geneva June 1998; Abstract 33162.

13 Ciria LM. Impact of zidovudine on perinatal HIV transmission in Mallorca Island, Spain. XII World AIDS Conference Geneva June 1998; Abstract 23314.

14 Galvaao NO, Silva CL, Naud PSV, Chaves EBM, Zachia SA, Larangeira M, et al. Reduction of maternal-infant transmission of human immunodeficiency virus type 1 with zidovudine (ZDV) treatment. XII World AIDS Conference Geneva June 1998; Abstract 12155.

15 Rakusan TA, Temple V, Hart L, Loechelt B, Rana S, Young M, et al. Use of zidovudine to reduce the risk of perinatal transmission of HIV infection in the Washington metropolitan area. XII World AIDS Conference Geneva June 1998; Abstract 12157.

16 Lorenzi P, Spicher VM, Laubereau B, Hirschel B, Kind C, Rudin C, et al. Antiretroviral therapies in pregnancy: maternal, fetal and neonatal effects. AIDS 1998;12:F241-7.

(Accepted 19 July 1999)

\section{Endpiece}

\section{There when needed}

God and the doctor we like adore

But only when in danger, not before;

The danger o'er, both are like requited,

God is forgotten, and the doctor slighted.

John Owen, c 1563-1622

Submitted by David Carvel, general practitioner locum, Glasgow 